\title{
The Role of Inflammation in Crohn's Disease Recurrence after Surgical Treatment
}

\author{
B. Sensi $\mathbb{D}^{1}{ }^{1}$ L. Siragusa $\left(\mathbb{D},{ }^{1}\right.$ C. Efrati, ${ }^{2}$ L. Petagna $\left(\mathbb{D},{ }^{1}\right.$ M. Franceschilli $\mathbb{D}^{1},{ }^{1}$ V. Bellato $\mathbb{D},{ }^{1}$

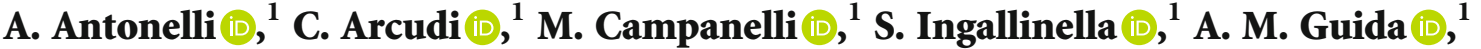 \\ and A. Divizia $\left(^{1}\right.$ \\ ${ }^{1}$ Department of Surgery, Tor Vergata University of Rome, Viale Oxford 81, 00133 Rome, Italy \\ ${ }^{2}$ Department of Gastroenterology, Ospedale Israelitico, Rome, Italy \\ Correspondence should be addressed to B. Sensi; brunosensi@outlook.it
}

Received 18 August 2020; Revised 4 December 2020; Accepted 8 December 2020; Published 28 December 2020

Academic Editor: Carlo Cavaliere

Copyright (C) 2020 B. Sensi et al. This is an open access article distributed under the Creative Commons Attribution License, which permits unrestricted use, distribution, and reproduction in any medium, provided the original work is properly cited.

\begin{abstract}
Introduction. Postoperative recurrence after surgery for Crohn's disease (CD) is virtually inevitable, and its mechanism is poorly known. Aim. To review the numerous factors involved in CD postoperative recurrence (POR) pathogenesis, focusing on single immune system components as well as the immune system as a whole and highlighting the clinical significance in terms of preventive strategies and future perspectives. Methods. A systematic literature search on CD POR, followed by a review of the main findings. Results. The immune system plays a pivotal role in CD POR, with many different factors involved. Memory Tlymphocytes retained in mesenteric lymph nodes seem to represent the main driving force. New pathophysiology-based preventive strategies in the medical and surgical fields may help reduce POR rates. In particular, surgical strategies have already been developed and are currently under investigation. Conclusions. POR is a complex phenomenon, whose driving mechanisms are gradually being unraveled. New preventive strategies addressing these mechanisms seem promising.
\end{abstract}

\section{Introduction}

Crohn's disease $(\mathrm{CD})$ is a chronic inflammatory bowel disease (IBD) affecting 1.5-213 persons per 100,000, depending on geographical location and lifestyle. Management of CD has become increasingly sophisticated and complex, yet no definitive cure exists. In fact, although the majority of $\mathrm{CD}$ patients will be treated surgically at least once in their lives, postoperative recurrence (POR) of the disease has proven virtually inevitable [1-5]. Endoscopic evidence of $\mathrm{CD}$ recurrence in the preanastomotic ileum is found in approximately $60 \%$ [6] of patients at six months and $80-90 \%$ at 12 months [7] from the index operation $[8,9]$. Endoscopic POR is not a synonym for clinical recurrence although generally the former heralds the latter [10]. In particular, 15-30\% of patients will complain of florid CD symptomatology at 12 months [11-14], 20-40\% at 24 months, and so on [15]. Re-do surgery occurs in up to $50 \%$ of patients with long-term follow-up [16].

The precise pathogenesis of postoperative recurrence is not known although many studies have shed light on the pathways involved. Inflammation is definitely the ultimate mechanism of tissue destruction that is reinitiated in POR. A deeper understanding of recurrence mechanisms may help clinicians and surgeons refine treatment and improve outcomes.

\section{Aim}

The authors' aim is to provide a comprehensive review of the processes involved in CD POR pathogenesis.

We will analyze how each component of the immune system has a part in CD POR pathogenesis, as well as 
immune function as a whole, and highlight its significance in relation to initiating factors and preventive strategies.

\section{Methods}

A systematic literature search was performed, followed by a narrative review summarizing the main findings. The systematic search was carried out on MEDLINE and Cochrane electronic databases to identify articles on CD POR. Keywords used were "Crohn recurrence," "Crohn surgery," and "Crohn inflammation." The search was followed by duplicate removal and rejection of not pertinent studies or not fulfilling inclusion criteria (Figure 1). Studies included were original articles that referred to the recurrence of Crohn's disease after including randomized controlled trials, prospective and retrospective cohort studies, and case reports. Excluded article types were narrative reviews, videos, letters, conference proceedings, and abstracts. Studies that were not considered pertinent after full-text review (i.e., not addressing postsurgical recurrence pathogenesis issue specifically) were also excluded. References of all included articles were checked for additional paper identification. Papers in languages other than English were excluded from the search (Figure 1).

We use the terms "recurrence" and "POR" in the text interchangeably and "relapse" when referring to the occurrence of symptoms after a period of medically induced remission.

\section{Pathogenesis}

The pathogenesis of Crohn's disease is a complex one, and its precise mechanisms are still largely unknown. However, it is clear that it results from an interplay of factors such as genetics, environment, and dysbiosis, leading to immune dysregulation. Postoperative recurrence of CD is possibly an even more obscure event, yet again, it is beyond doubt that the host's immune system plays a major role. A summary of pathogenic mechanisms can be found in Table 1 and Figure 2 .

\section{Innate Immune System}

The innate immune system represents the body's first line of defense. It includes physical barriers (such as cells of the epidermis or mucosa, which can also actively contribute with their secretions) and immune cells such as granulocytes, monocytes, dendritic cells, and natural killer (NK) lymphocytes. Most of these elements have been shown to be involved in CD, but little evidence exists on the innate system's role in CD POR. Nonetheless, mechanisms involved in disease pathogenesis may also be implied in disease recurrence, while others appear to be specific for POR.

\subsection{Derangements in the Pattern Recognition Receptor and} Other Genes. First, genetic analysis has identified a number of genes associated with greater odds of recurrence. The first gene to be correlated to CD has been NOD2/CARD15. This gene is an intracellular pattern recognition receptor (PRR), involved in the recognition of peptidoglycans and activation of innate immune responses. While its role in CD pathogenesis is certain, its implication in recurrence, although reason- able, is less definite and a meta-analysis [17] has failed to demonstrate a significant association [18]. A more recent study has identified instead, at multivariable analysis, an independent association between recurrence and a particular NOD2 polymorphism, rs2066844, which was not previously investigated [19]. Another gene, SMAD3, has never been linked to CD pathogenesis but was found to be an independent predictor of recurrence after ileocolic resection [20]. The authors speculate that SMD3 polymorphism may pathologically increase the scarring process after surgery and enhance fibrosis, resulting in accelerated recurrence and the need for reoperation. Finally, a recent study on 137 patients with bowel resection for CD analyzed more than 200 genetic variables [21]. Only CARD8, a gene that is highly expressed in monocytes and in the gut epithelium was independently predictive of surgical recurrence. CARD8 is a negative regulator of nuclear factor $-\kappa \beta(\mathrm{NF}-\kappa \beta)$, which is in turn a suppressor of apoptosis, and interacts with the inflammasome, which mediates IL- 1 production and has a role in the maintenance of gut homeostasis. These functions place CARD8 as a regulator of innate and adaptive immunity. However, the exact pathways through which CARD8 enhances surgical recurrence have yet to be elucidated.

5.2. Matrix Metalloproteinases. Matrix metalloproteinases (MMPs) are a group of endoproteinases with proteolytic activity directed toward various matrix proteins, secreted by inflammatory cells (chiefly macrophages). Tissue inhibitors of metalloproteinases (TIMPs) regulate their activity. In the inflamed mucosa of CD, the MMP/TIMP balance is tipped in favor of MMPs. One study found a TIMP-1 variant to be correlated to surgical recurrence but not to diagnostic recurrence, implying a relatively mild- or late-onset influence [22]. Investigators have also shown that higher expression of TIMP-1 and TIMP-2 in the noninflamed mucosa after resection was protective from diagnosis of recurrence and from repeated resections. The magnitude of this effect is quite impressive: the median time to recurrence in patients with low levels of TIMP-1 was 10 years, compared to 17 years in the high expression group.

5.3. Cells of the Innate Immune System, Their Response to Commensal Microbiota, and Clinical Implications. Neutrophils represent the main kind of cell involved initially in acute inflammation and are the main actor in the typical cryptic abscesses of IBD. No study specifically correlates these cells to $\mathrm{CD}$ recurrence, but their presence in intestinal nervous plexuses has been implicated in some studies (see Immune Function as a Whole). Macrophages are very important innate immunity cells, which not only are major actors of acute inflammation but also are also involved in chronic inflammatory states and represent a major link with acquired immunity. Their role in CD pathogenesis is multifaceted and includes the production of proinflammatory cytokines (in response to inappropriate TLR stimulation), generation of granulomas, mediation of fibrosis, and disruption of intestinal epithelial barrier function [23-25]. Less is known about specific actions in POR. Their infiltration in the mucosa of the neoterminal ileum of POR-free patients suggests their driving role of 


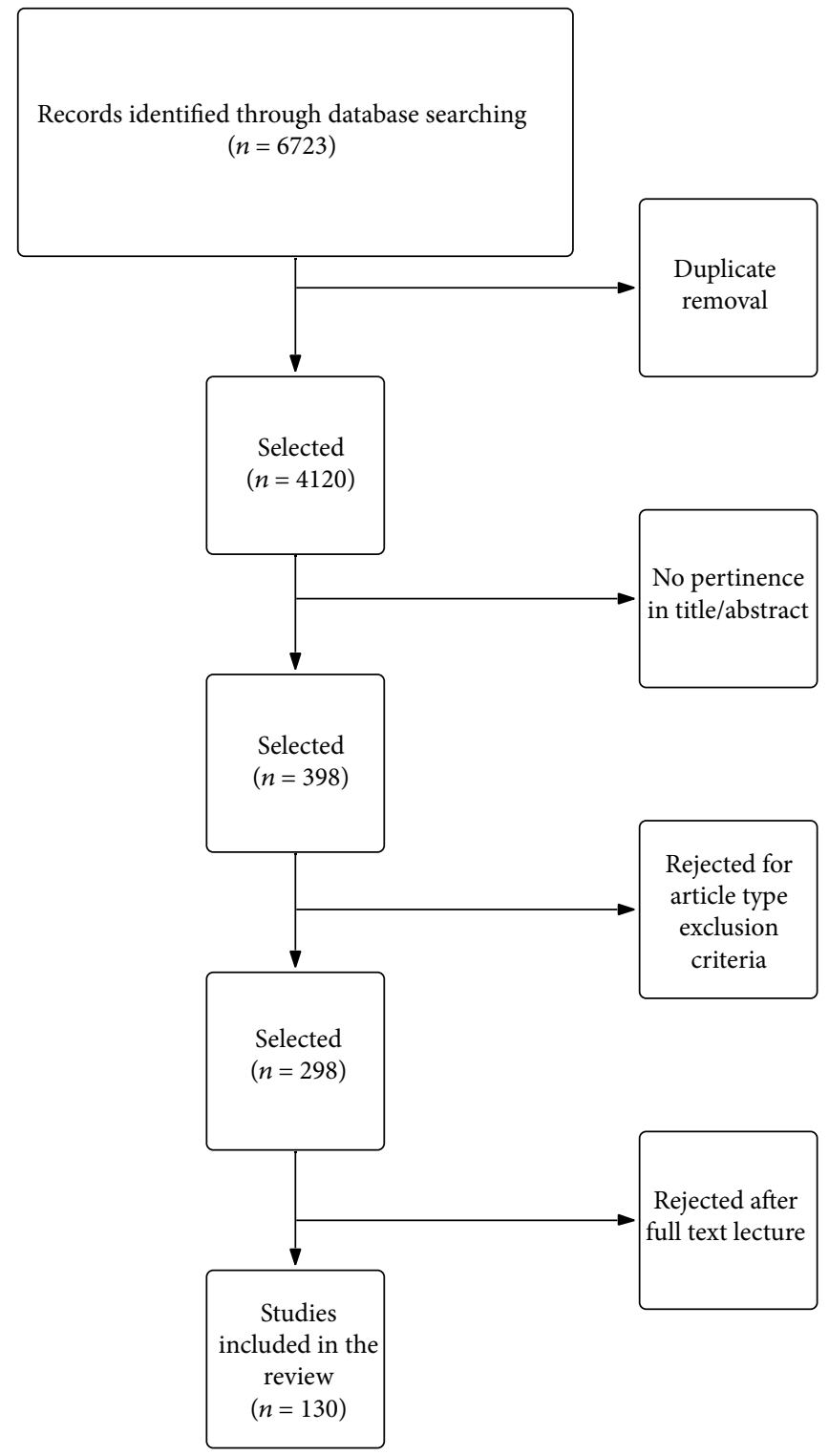

FIGURE 1: Systematic review methodology.

inflammatory events that bring about recurrence [26]. One mechanism through which they may be involved in POR has been highlighted in experimental studies that involve $\mathrm{CX}_{3} \mathrm{CR} 1^{\text {hi }}$ cells. These are mucosal resident mononuclear phagocytes, whose role is to capture luminal bacteria, in an effort to compartmentalize the immune response and avoid inflammation. These cells therefore represent the "second line" of defense. While previously reported to be a nonmigratory population, Diehl et al. [27] have shown in experimental models that they can actually be endowed with the ability to migrate and traffic bacteria (or their antigens) to mesenteric lymph nodes, key immune inductive sites. This may well start the inflammatory process. Not only have the authors described this phenomenon but, even more interesting, they also have unveiled a tight connection with luminal microbiota. In fact, it appears that dysbiosis is a potent activator of bacterial trafficking through this route. This mechanism has not been studied in recurrence. The effects of microbiota on recur- rence have been studied. Sokol et al. have demonstrated that surgery produces profound changes in ileal microbiota, reducing dysbiosis typical of CD such as increased Gammaproteobacteria and declined Lachnospiraceae and Ruminococcaceae [28]. The magnitude of these changes was significantly reduced in patients who developed early postoperative endoscopic recurrence, so much so that biopsies at follow-up showed that diversification in microbiota decreased in parallel with an increase in the Rutgeerts score. The authors went so far as to develop a predictive score for recurrence that was based primarily on microbiota composition at surgery. Unfortunately, this score was not applicable to patients who had undergone antibiotic therapy in the last month before surgery (a considerable fraction of CD patients) and even more importantly did not predict the outcome in patients who were administered anti-TNF preventive therapy. Putting these facts together, one might conclude that dysbiosis reestablishment after surgery induces a new bout of bacterial trafficking, 
TABLE 1: Elements involved in CD recurrence.

\begin{tabular}{|c|c|c|c|}
\hline Domain & Specific element & Putative mechanism of action & $\begin{array}{l}\text { Level of } \\
\text { evidence }\end{array}$ \\
\hline Innate immune system & $\begin{array}{c}\text { NOD2 gene } \\
\text { rs2066844 polymorphism }\end{array}$ & $\begin{array}{l}\text { Improper activation of the immune response } \\
\text { (pattern recognition receptor) }\end{array}$ & Low-moderate \\
\hline Innate immune system & SMAD3 & Drive fibrosis after initial surgical scarring & Low \\
\hline Innate immune system & CARD8 & IL-1 production, immune dysregulation & Low \\
\hline Innate immune system & Matrix metalloproteinases & Initiation of inflammation/fibrosis & Low-moderate \\
\hline Innate immune system & Macrophages & Bacterial trafficking to mesenteric nodes & Low \\
\hline Innate immune system & Dendritic cells and basophils & $\begin{array}{l}\text { Set up a potent and durable acquired immune } \\
\text { response }\end{array}$ & Low \\
\hline Adaptive immune system & Effector T-cells & Bring about most recurrent inflammation & Moderate-high \\
\hline Adaptive immune system & Memory T-cells & $\begin{array}{l}\text { Persist after resection in mesenteric lymph } \\
\text { nodes (and blood to a lesser degree) and } \\
\text { conserve immunological memory }\end{array}$ & Moderate-high \\
\hline Adaptive immune system & B-cells & $\begin{array}{l}\text { Produce anti-GM-CSF immunoglobulins; } \\
\text { others }\end{array}$ & Low \\
\hline $\begin{array}{l}\text { Immune system as } \\
\text { a whole }\end{array}$ & Dysbiosis & Increased bacterial trafficking; others & Low \\
\hline $\begin{array}{l}\text { Immune system as } \\
\text { a whole }\end{array}$ & $\begin{array}{c}\text { Increased mucosal IL-6; decreased mucosal IL- } \\
10 \text {; RNASET2 polymorphism }\end{array}$ & Increase mucosal inflammation & Low \\
\hline $\begin{array}{l}\text { Immune system as } \\
\text { a whole }\end{array}$ & Inflammation at resection margins & Persistence of activated cells & Low \\
\hline $\begin{array}{l}\text { Immune system as } \\
\text { a whole }\end{array}$ & Myenteric and submucosal plexitis & Unknown & Low \\
\hline $\begin{array}{l}\text { Immune system as } \\
\text { a whole }\end{array}$ & Diet & $\begin{array}{l}\text { Stimulate the immune system through poorly } \\
\text { understood mechanisms }\end{array}$ & Low-moderate \\
\hline Other risk factors & Smoking & $\begin{array}{l}\text { Unknown; may increase mucosal T-cell } \\
\text { hyperclonality }\end{array}$ & High \\
\hline Other risk factors & $\begin{array}{l}\text { Penetrating disease at index surgery, perianal } \\
\text { disease, prior intestinal surgery extensive small } \\
\text { bowel resection }(>50 \mathrm{~cm})\end{array}$ & Unknown & High \\
\hline
\end{tabular}

immune induction, and inflammation. This model is purely speculative, and it is likely that immune memory would have a greater role than a new activation. Nonetheless, if it does have a role, two strategies would have the potential to maintain the surgery-induced changes in microbiota and slow down recurrence: probiotic administration and fecal transplantation. A multicenter randomized controlled trial investigated the effect of probiotics on early endoscopic recurrence but failed to demonstrate a protective effect [29]. It has to be said that in this study, a specific probiotic strain, Lactobacillus johnsonii, was used: whether other probiotics could better serve this purpose and revive this practice is unknown. Fecal transplantation brings the "probiotic strategy" to the extreme. This intervention has been extensively shown to be effective in the treatment of ulcerative colitis, but high-quality evidence lacks in CD. No randomized trial exists to date [30], and there is considerable heterogeneity in many aspects of therapy including donor selection, fecal conditions (fresh/frozen), delivery route, and antibiotic pretreatment [31-33]. Metaanalyses of cohort studies have shown that it may have a good rate of clinical remission induction [34]. To date, no study exists on the evaluation of this therapy after surgery. Given the strong rationale for its use, this may indeed be the focus of upcoming trials. Another fundamental function of innate immunity is that of dendritic cells (DCs). They are potent antigen-presenting cells whose role in $\mathrm{CD}$ is well established: activating site-specific Th1 and Th17 responses [35-38]. Specific populations of dendritic cells direct inflammation and dictate CD location (by inducing homing markers) [39, 40]. These cells therefore set up a potent and durable immune response that is thought to be the principal driver of $\mathrm{CD}$ recurrence. In this way, they drive recurrence indirectly. Whether they also play a more direct role by reviving this mechanism after resection is not known to date. Basophils have been recently found capable of serving a similar function to DCs [41].

\section{Acquired Immune System}

The acquired immune system represents the body's more refined defense machinery. It mainly relies on the action of activated lymphocytes that are capable of initiating, amplifying, and perpetuating an adaptive, antigen-specific response. Lymphocytes include B-cells responsible for humoral immunity and T-cells, which conduct the cell-mediated arm.

6.1. T-Cells. Cell-mediated immunity could be the real protagonist of the recurrence process. There is evidence that 


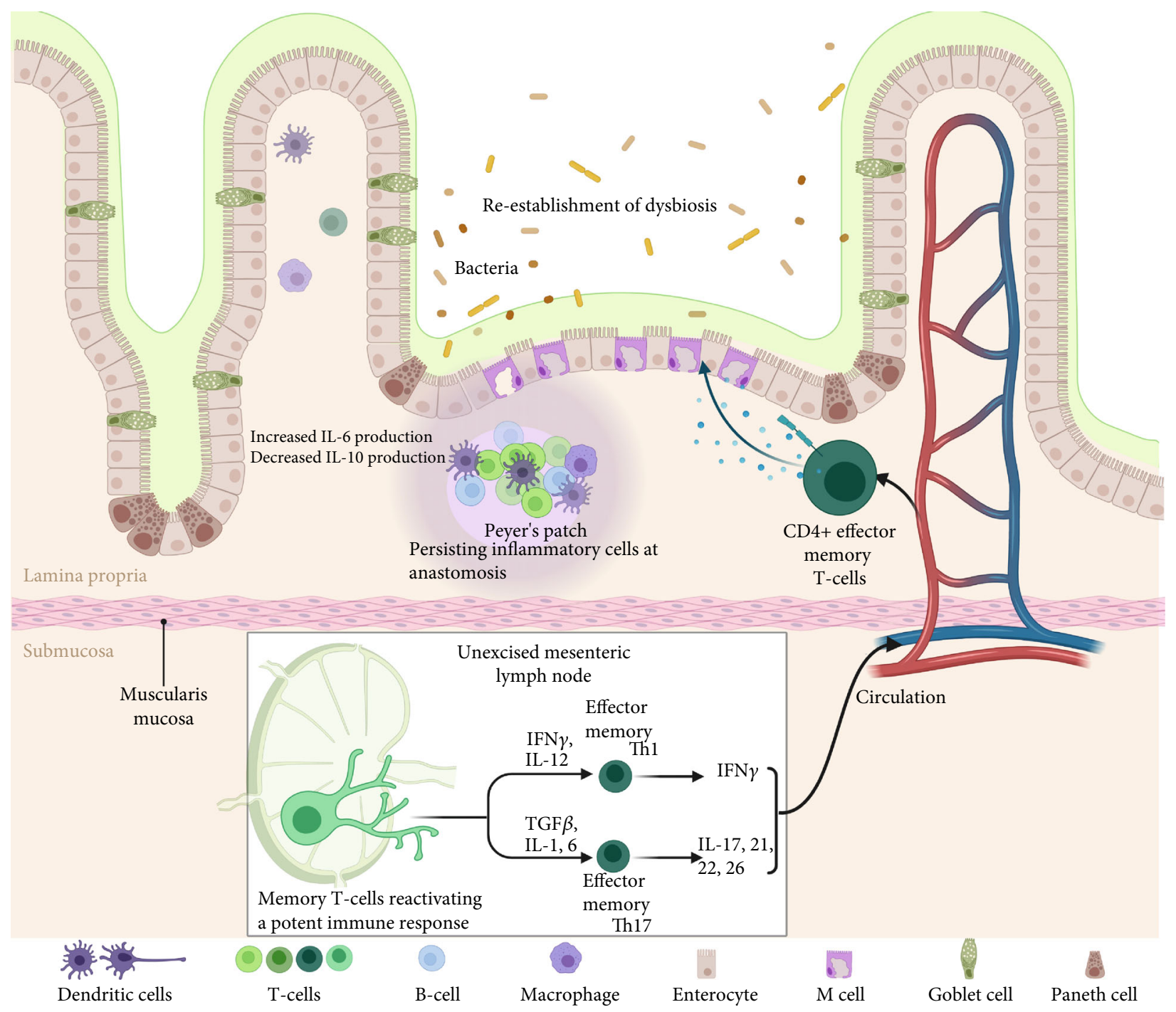

Figure 2: Pathogenesis of Crohn's disease recurrence. Created with https://BioRender.com

the mucosa of the affected bowel harbors significantly increased clonal expansions of T-cells compared to that of healthy controls [42]. Whether this clonality principally concerns CD4+ or CD8+ cells has not been consistent, as both have been implicated in different studies [42, 43]. In any case, the presence of high clonality seems to be the harbinger of endoscopic recurrence, with greater percentages of clones associated with a greater risk of recurrence [42]. Furthermore, these highly expanded clones are different from clones found in healthy tissue, supporting a pathogenic role of Tcells [44]. The T-cell receptor (TCR) repertoire seems to be different in different individuals, with no commonly targeted antigens, highlighting the singularity of each CD patient's immune response [42]. Another observation was that the TCR repertoire in the mucosa could change with surgical resection. Postoperative persistence of a TCR repertoire similar to that before resection also correlates to the development of endoscopic recurrence [42]. In one study, the investigators were capable of identifying a particular clone, highly enriched in active $\mathrm{CD}$ tissues, and found its presence to be correlated to the severity of endoscopic recurrence (based on Rutgeerts score) [44]. Another study identified a subset of T-cells, CD4+NKG2D+ T-cells, whose presence at the ileal mucosal margins of resection predicted endoscopic disease recurrence [43]. In fact, this subset was found to be persistent in the mucosa of patients with recurrence. CD4+NKG2D+ T-cells display high expression of tumor necrosis factoralpha (TNF- $\alpha$ ) and other proinflammatory and cytotoxic molecules. Possibly, they would be left behind in the macroscopically healthy bowel and then induce recurrence. It is unclear however how they (being already present before operation) would induce active CD only after surgery. An alternative and more consistent explanation would be that they persist in large numbers in the mesenteric lymph nodes draining the resected bowel (which instead are not removed in current $\mathrm{CD}$ surgery) and are then free to home back into the neoterminal ileum. In fact, lymph nodes not only are a site of immune induction but also represent the anatomical location where the majority of memory T-cells reside [45, 46]. Therefore, mesenteric lymph nodes (MLNs) may be 
reasonably considered the dwelling of immune memory in CD. Bsat et al. [36] have studied MLNs of CD patients in depth and found them to be enriched in Th17 memory Tcells and in particular effector memory Th17 cells (TEM). The same group has also elucidated an IL-12-dependent pathway through which these memory cells are activated in the MLN and switched to a Th1 phenotype (i.e., cytokine/molecular profile) before being recruited back to the mucosa through homing mechanisms. This places the MLN at the center of a memory-driven immune reactivation in CD and therefore, potentially, of recurrence. Enhancement of MLN in imaging studies is, in fact, predictive of active disease [47]. The so-called trafficking blocking strategy, based on the fact that lymphocytes have to home back to the, until then, healthy gut from the nodes where they reside, has been given much prominence in recent drug development with promising ongoing trials [48].

Immunological memory was also implicated by genetic studies on BACH2 (a highly conserved transcription factor that is a fundamental element in the maturation of B-lymphocytes and differentiation of T-cells, especially in regulatory T-cells) which independently correlate it to surgical recurrence [49]. The authors speculate the underlying mechanism to be the inability to memorize an appropriate (tolerant) response to luminal antigens.

6.2. B-Cells. The part played by B-cells in CD inflammation is less clear [50]. So far, the most studied immunoglobulins have been peripheral Anti-Neutrophil Cytoplasmic Antibodies (pANCA) and Anti-Saccharomyces cerevisiae Antibodies (ASCA). Taken together, they are good serologic markers for $\mathrm{CD}$. Other antigens eliciting a humoral response in CD are Omp-C (outer bacterial membrane protein, E. coli-derived), CBir1, A4-Fla2, and Fla-X (flagellin subunits, Clostridiumderived). In one study, anti-Fla-X positivity at baseline was associated with endoscopic recurrence at 18 months while anti-Omp-C with multiple surgeries [51]. The significance and the processes underlying these findings are yet unclear. Antibodies could be inducing recurrence also through the neutralization of protective cytokine signaling. GranulocyteMacrophage Colony-Stimulating Factor (GM-CSF) enhances innate immune responses to luminal microbial antigens, thereby confining inflammation, avoiding antigen trafficking and activation of secondary immunity, and contributing to homeostasis. Anti-GM-CSF antibodies have been recorded in patients with $\mathrm{CD}$, and their titers positively correlated with a shorter time to the second surgery [52].

It is possible that serology will be eventually used to predict the postoperative course and identify patients who would profit from a more aggressive, proactive treatment strategy.

\section{Immune Function as a Whole}

Some factors that have been associated with recurrence cannot easily be categorized as "innate" or "adaptive" immunity but have to be considered affecting the immune system as a whole.
7.1. Cytokines. Cytokines are the signaling molecules of the immune system. They contribute to a variety of functions and are fundamental for a proper inflammatory response to take place. Some specific cytokines are known to be involved [53-59] and represent current therapeutic targets, others have been identified, and their targeting holds promise. In one study on 36 patients undergoing bowel resection, IL-6 was found to be elevated in most patients despite clinical remission, indicating persistent subclinical (systemic) inflammation through the IL-6-C-reactive protein (CRP) cascade $[60,61]$. Patients with surgical recurrence of their disease had particularly high IL-6 levels, which resulted in a significant predictor of recurrence in this series. Yet this was extrapolated from only three patients, and two of them had recurred within 5 months.

Even though very early surgical recurrence is a possibility, this more often represents a complication of the first intervention or preexisting disease that was overlooked or judged nonsignificant at the first operation. Nonetheless, this study highlights the ongoing inflammation that underlies the postoperative $\mathrm{CD}$ course and eventually recurrence. More evidence on the subject comes from a Japanese group [62]. They took blood samples and ileal biopsies from 36 resected patients: 16 of them had clinical recurrence within 1 year. In this group, only ileal mucosal IL-6 levels correlated significantly with clinical recurrence, but not serum possible that patients with surgical recurrence are a group with more aggressive and advanced disease and therefore present high IL-6 levels systemically rather than only at the primary inflammatory site. Reduction of anti-inflammatory cytokines is another mechanism observed to correlate with endoscopic lesions after surgery. In particular, IL-10 levels in the ileal mucosa predict the development of postoperative recurrence. Different IL-10 haplotypes exist and are associated with greater or lesser production of the cytokine, yet these were not able to predict recurrence [63]. It has been therefore speculated that other local environmental factors, so far not predictable, are responsible for IL-10 production in the mucosa. RNASET2, a gene shown to be involved in enhancement of IFN $\gamma$ production (the main cytokine involved in Th1 responses), has been observed to be associated with more severe recurrence (Rutgeerts score > 2) and, in line with this, to shorten time to repeat surgery [64]. A putative mechanism would therefore be an enhancement of adaptive cellular immunity and a quicker and more severe postoperative reestablishment of disease. Other observations come from direct clinical practice. The most used drug for the prevention of postoperative recurrence is infliximab, a monoclonal antibody directed against TNF- $\alpha$. Infliximab is of proven benefit in this situation and is recommended by current guidelines. In particular, there is high-quality evidence from a randomized controlled trial that it reduces the incidence of endoscopic recurrence (by a half!) at one year from surgery [65]. At the same time, it did not reduce clinical recurrence in the same period. Yet, clinical recurrence occurs for the majority of patients beyond this period, and therefore, the real clinical impact of infliximab has yet to be revealed with longer-term follow-up. Moreover, there is some evidence pointing to fewer operations for CD during the anti-TNF era [66]. This may 
indeed have an impact on surgical recurrence rates although this is so far unproven. Finally, the effect of anti-TNF therapy on endoscopic remission may be more pronounced in patients who were previously naïve or had undergone therapy with only one anti-TNF agent [67].

7.2. Inflammation in Resection Margins and Intestinal Nervous Plexuses. Another analyzed factor is histologic evidence of inflammation at resection margins. Inflammation is defined in different studies in many different ways and includes inflammation of the mucosa, of the submucosa, and even of the nerve plexuses. The first reports on microscopic evidence of inflammation at resection margins have done much to shape the current concepts of surgery for $\mathrm{CD}$. It was shown that the presence of features of chronic inflammation or diagnostics of $\mathrm{CD}$ at resection margins did not influence recurrence rates $[68,69]$. This was the basis to advocate as short a resection as possible, on the macroscopically healthy bowel [70]. This approach has been the standard practice for decades and is thought to have reduced the risk of short bowel syndrome. Lately though, this subject has been revived by new studies that have given us a slightly different perspective. Poredska et al. have reported resection margin inflammation (at both the proximal and distal margins) to be related to endoscopic POR [71]. In their study, "inflammation" included signs of both the acute and chronic forms. One recent report has focused instead on active inflammation at resection margins (defined as a Geboes score $>3$ ) and found that its presence on the colonic margin was the only histologic predictive factor for clinical POR [72]. They failed to demonstrate any correlation for other histologic factors like myenteric plexitis and granulomas. Other investigators have studied both factors widely, so far with nondefinitive results. Granulomas' presence in the histologic specimen seems to predict surgical POR and a shorter time to the second surgery in a large meta-analysis [73]. Myenteric plexitis was reported to be a risk factor for endoscopic POR in a landmark study by Ferrante et al. in 2006 [74]. More research focused on submucosal plexitis and found a similar association (again, not consistently) $[75,76]$. Finally, one study incriminated increased enteric plexus glial cells [77]. The trouble to compare these studies is that most are retrospective and that they define "inflammation," "plexitis," etc. in different ways, as there is no consensus or grading system specific for these features in CD [78]. In fact, results are variable as to which feature is predictive as much as where to assess it and how. In general, predicting POR through a baseline histologic assessment on the index specimen is a promising approach but one that still requires confirmation and refinement before entering common clinical practice (or trials).

7.3. Diet. Another very interesting factor is diet. CD patients are at high risk of malnutrition, in both the active and quiescent diseases, and dietary evaluation is fundamental in improving nutritional status, thus ameliorating disease outcomes [79]. Some investigators have specifically assessed diet influence on POR. In particular, an elemental diet (ED) has been advocated to reduce bowel inflammation. Most studies on the subject come from Japan, where it is used as standard therapy, in contrast to the USA or Europe [80]. It consists mainly of amino acids, which do not possess any intrinsic antigenicity and therefore are bereft of proinflammatory capacity. While large experience has been accumulating with its use in relapses, there are relatively few studies in the postoperative setting. The major limitation to ED is that patient compliance is generally low as it can be quite distasteful. When large amounts of calories have to be taken as ED, the use of a self-inserted nasogastric tube is commonly advised. This practice has its own obvious limitations, and adherence is limited. Yamamoto et al. conducted a prospective controlled study on long-term postoperative ED in 40 patients. Patients were not randomized but arbitrarily assigned to non-ED vs. ED based on predicted compliance with the regimen. The two groups differed significantly at 1 year in terms of endoscopic remission [81]. At 5 years, clinically significant recurrence was impressively in favor of the ED group (10 vs. 45\%) [82]. Surgical recurrence also showed a trend in favor of the ED group but was not significant. Another study showed similar results on endoscopic POR [83]. Despite fascinating results, they should still be considered preliminary as the number of patients was small and the study design was not devoid of bias. Today, the method has not entered common practice and has not gathered excessive interest in western countries.

\section{Other Risk Factors}

Other risk factors for POR that are not strictly related to the immune system are as follows: penetrating disease at index surgery, perianal disease [84], prior intestinal surgery extensive small bowel resection $(>50 \mathrm{~cm})$, and smoking $[84,85]$. No clear explanation exists for any of these: probably, they simply herald a more aggressive phenotype. Smoking is undoubtedly the most studied with a higher level of evidence [86-89]. An interesting finding by Allez et al. is that smoking is associated linearly with hyperclonality of T-cells in the affected mucosa [42]. This data therefore links smoking to the actual inflammatory processes that lead to recurrence: specific CD4+ T-cell clones.

Ileocolic disease may recur more often than disease at other sites when assessed morphologically, yet it is less often symptomatic, and rates of clinical recurrence are lower [7]. One study has tried to put these elements together in a nomogram to predict early disease recurrence [90]. Interestingly, they have also included low preoperative serum albumin and "excessive perioperative inflammation" (expressed as high CRP levels). This attractive instrument however has not been widely validated so far.

\section{Prevention}

We have so far analyzed a number of risk factors for the development of $\mathrm{CD}$ recurrence. The usefulness of this knowledge would be to detect patients in greater peril and to use treatment strategies accordingly. This concept is already in place for what concerns postoperative drug treatment, with antiTNF and immunosuppressants being used in patients at high risk or with signs of endoscopic POR. Other pharmaceutical 
targets will surely be investigated in the coming years. Different medical pathways may also prove of benefit in the future such as fecal transplantation and hematopoietic stem cell transplantation. New surgical approaches are also promising. A summary of preventive strategies may be found in Table 2.

9.1. Hematopoietic Stem Cell Transplantation. In the last decade, much work has been focused on one objective: resetting the entire immune system. This may be accomplished through a treatment well known to hematologists: hematopoietic stem cell transplantation (HSCT).

HSCT for CD has been inspired by two parallel phenomena. The former was the observation of prolonged (yet not indefinite) remission in patients with HSCT performed for other (hematologic) indications [91]. The latter was the success of this strategy in patients suffering from other autoimmune diseases like systemic sclerosis and systemic lupus erythematosus. Of course, given the high toll requested by allogenic HSCT, trials have used autologous HSCT. Many investigators have reported encouraging results [92]. The main drawback of this approach is the high rate of complications and mortality that persists even with the autologous form [93]. The highest level of evidence comes so far from the ASTIC trial. This trial failed to show the superiority of HSCT in achieving the primary outcome [94]. Yet, the primary outcome was an extremely ambitious one: sustained disease remission at 12 months, defined as a composite of Crohn's Disease Activity Index (CDAI) < 150 , no active treatment for at least 3 months, and no endoscopic evidence of disease (erosion/ulceration). A different analysis of data coming from the same trial, using conventional endpoints used in trials for CD, highlighted a significant benefit in the treatment arm [95]. When relapse occurs, patients tend to respond to conventional treatment to which they had become refractory prior to transplantation [96]. A new randomized trial has successively been set up, ASTIClite, using a lower dose regimen in an effort to maximize the benefit/hazard ratio [97]. No trial is currently evaluating HSCT in the postoperative setting.

9.2. Surgical Approach and Procedures. Surgical intervention has also been at the center of much research in an endeavor to diminish POR, but the surgical approach did not appear to have any consequence on the short- or long-term disease course [98-104]. Nevertheless, the following are currently the more promising research fields.

9.2.1. Anastomosis. The anastomosis type and fashioning technique have also been the objective of many investigations. Stapled anastomosis (despite boasting lower leak rates) is not superior to handsewn in terms of recurrence rates [105]. Exactly the same considerations are true for side-toside vs. end-to-end anastomosis [106, 107]. In an effort to reduce recurrence, some investigators have proposed new surgical techniques [108, 109]. Kono et al. published in 2011 their first report on a new anastomotic technique [108]. Their results were impressive with an enormous reduction in surgical recurrence rates at 5 years when compared with historical cohorts. The authors ascribe this magnificent effect on their particular technique, which was designed to maintain the anastomosis diameter and dimensions. It is not clear how this would then affect recurrence rates, as CD recurrence notoriously occurs in the preanastomotic neoterminal ileum, rather than at the anastomotic site. Nonetheless, their results have been reproduced in a series from a single center in the USA [110] and another from multiple centers in Japan [111]. One study [112] showed superiority against end-to-end (EE) anastomosis, yet the latter is not recommended by issued guidelines [113] due to its poorer results compared to standard latero-lateral anastomosis. Finally, a recent randomized controlled trial documented benefits in terms of 6 and 12 months of endoscopic recurrence rates and 24 months of clinical recurrence rates [114]. This study represents an enormous effort. Yet, a bias that cannot be overestimated was that the endoscopist evaluating patients at follow-up was not blinded to the procedure performed. Given the known operator dependence of the Rutgeerts score, results from this trial cannot be overly reliable. Although all reports vouch for the safety of the Kono-S anastomosis, it is technically demanding and time-consuming. To date, the literature produced so far on this interesting technique is not entirely trustworthy and doubts about its real efficacy remain.

9.2.2. Strictureplasty. An alternative to resection can be strictureplasty. Its role is well defined in some cases (where its bowel-sparing benefits are relevant) and less so in others. In any case, long-term results may be comparable to resection, although this is not clear and a high-quality head-to-head comparison is lacking. The most interesting feature of strictureplasty regards the Michelassi configuration. This side-to-side isoperistaltic strictureplasty (SSIS) has been reported to induce healing of the mucosa as seen with postoperative endoscopy. The mechanisms underlying this prodigious feat are currently unknown although it has been suggested that resolution of chronic obstruction would interrupt the perpetuation of active inflammation [115-117]. Surgical recurrences after SSIS are comparable to those reported for resection, around $20-30 \%$ in the long term (5-10 years) at the strictureplasty site $[118,119]$. Nonetheless, SSIS is rarely performed for its technical complexity and the infrequency of its necessity: in the same department where it was ideated, only $3 \%$ of IBD patients undergo this procedure [118].

9.2.3. Mesenteric Excision. Coffey et al. have shown a significant decrease in postoperative surgical recurrence in their retrospective series of patients, by adopting a more radical, "mesenterybased" surgical approach. Despite the magnitude of reported results being impressive, the inherent limitations in study design and specific aspects of the work lend themselves to perplexity and criticism [120]. Furthermore, the rationale for its use is absolutely scarce: very little literature supports the hypothesis of a "mesentery-driven" disease [121-128]. On the contrary, some evidence exists that important proinflammatory mechanisms are unique to the mucosa and cannot be observed in the mesentery [128]. Finally, the proposed approach seems very difficult to standardized as the correct amount of the mesentery to be removed is unknown and the suggested "mesenteric disease score" to evaluate the severity 
TABLE 2: New perspectives for recurrence prevention.

\begin{tabular}{|c|c|c|c|}
\hline Domain & Prevention strategy & Description & Rationale \\
\hline Medical & Fecal transplantation & Transfer of fecal bacteria from healthy subjects & Avoid dysbiosis reestablishment \\
\hline Medical & $\begin{array}{l}\text { Hematopoietic stem cell } \\
\text { transplantation }\end{array}$ & $\begin{array}{l}\text { Bone marrow ablation followed by } \\
\text { autotransplantation of multipotent stem cells }\end{array}$ & Reset immune system \\
\hline Surgical & Michelassi strictureplasty & Side-to-side isoperistaltic strictureplasty & $\begin{array}{c}\text { Induce mucosal healing by resolution of chronic } \\
\text { obstruction }\end{array}$ \\
\hline Surgical & Kono anastomosis & $\begin{array}{c}\text { Fashioning of antimesenteric wide lumen } \\
\text { anastomosis }\end{array}$ & $\begin{array}{l}\text { Increase the diameter and stability/durability of } \\
\text { anastomosis }\end{array}$ \\
\hline Surgical & Mesenteric excision & Excision of the associated mesentery & Removal of pathological tissue \\
\hline Surgical & $\begin{array}{l}\text { Pathophysiological } \\
\text { excision }\end{array}$ & Excision of draining mesenteric lymph nodes & $\begin{array}{l}\text { Removal of most memory T-cells, drivers of } \\
\text { inflammation and recurrence }\end{array}$ \\
\hline
\end{tabular}

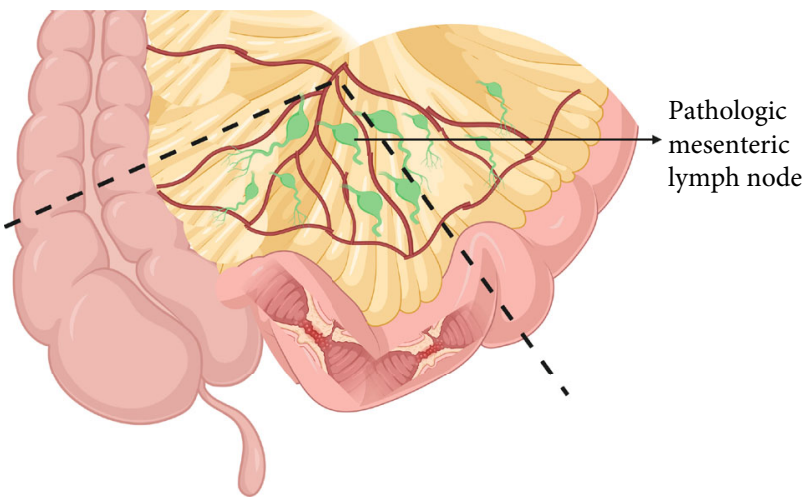

Figure 3: Pathophysiological excision for Crohn's (PEC). Created with https://BioRender.com

of mesenteric affection probably suffers from great interobserver variability [129].

9.2.4. Pathophysiological Excision. A novel approach might be that of Sica et al., presented at the Italian Group for Inflammatory Bowel Disease (IG-IBD) in 2020, but the trial is only just started (NCT04623476). This approach entails a resection of all the nodes draining the affected bowel along with the bowel itself, following a medial to lateral oncologic approach in colorectal surgery (Figure 3 ). The theoretical advantage is that of removing the main actors in postoperative recurrence: memory T-cells residing in the nodes. For this reason, the authors have named it "pathophysiological excision for Crohn's" (PEC). Probably, the remaining lymphocytes would have the potential to restart a full-blown syndrome. However, one interesting fact in this regard is that when lymph nodes are completely removed together with the whole bowel, the remaining circulating lymphocytes are practically incapable of reproducing CD features in a small bowel transplant [130, 131]. Nonetheless, this phenomenon (lack of proper recurrence) may be attributed to features of the transplant itself (such as different antigenicity or microbiota) or immunosuppression rather than a failure of circulating memory cells and therefore cannot be considered conclusive evidence in this sense. Nonetheless, the pathophysiological excision approach is one that is easily standardized, familiar to surgeons (from oncologic surgery), and supported by a rationale. Results of this trial could extend our knowledge and armamentarium.

\section{Summary/Conclusion}

Pathogenesis of postoperative Crohn's disease recurrence is complex and multifactorial. A primary role is surely reserved for memory T-lymphocytes. These cells migrate, following resection, from the persisting (disease-burdened) mesenteric lymph nodes to the healthy preanastomotic mucosa to perpetuate the inflammatory status. A number of diverse interventions to reduce recurrence are under evaluation, but strategies influencing the abovementioned mechanism harbor the promise of success and perhaps, one day, of cure.

\section{Data Availability}

The data supporting this review are from previously reported studies and datasets, which have been cited.

\section{Conflicts of Interest}

The authors declare that there is no conflict of interest regarding the publication of this article.

\section{References}

[1] J. Burisch and P. Munkholm, "The epidemiology of inflammatory bowel disease," Scandinavian Journal of Gastroenterology, vol. 50, no. 8, pp. 942-951, 2015.

[2] L. Peyrin-Biroulet, E. V. Loftus, J. F. Colombel, and W. J. Sandborn, "The natural history of adult Crohn's disease in population-based cohorts," The American Journal of Gastroenterology, vol. 105, no. 2, pp. 289-297, 2010.

[3] P. Munkholm, E. Langholz, M. Davidsen, and V. Binder, "Disease activity courses in a regional cohort of Crohn's disease patients," Scandinavian Journal of Gastroenterology, vol. 30, no. 7, pp. 699-706, 2009.

[4] B. Sands, J. E. Arsenault, M. J. Rosen et al., "Risk of early surgery for Crohn's disease: implications for early treatment strategies," The American Journal of Gastroenterology, vol. 98, no. 12, pp. 2712-2718, 2003.

[5] I. C. Solberg, M. H. Vatn, O. Høie et al., "Clinical course in Crohn's disease: results of a Norwegian population-based ten-year follow-up study," Clinical Gastroenterology and Hepatology, vol. 5, no. 12, pp. 1430-1438, 2007.

[6] A. Orlando, F. Mocciaro, S. Renna et al., "Early postoperative endoscopic recurrence in Crohn's disease patients: 
data from an Italian Group for the study of Inflammatory Bowel Disease (IG-IBD) study on a large prospective multicenter cohort," Journal of Crohn's \& Colitis, vol. 8, no. 10, pp. 1217-1221, 2014.

[7] S. Onali, C. Petruzziello, E. Calabrese et al., "Frequency, pattern, and risk factors of postoperative recurrence of Crohn's disease after resection different from ileo-colonic," Journal of Gastrointestinal Surgery, vol. 13, no. 2, pp. 246-252, 2009.

[8] S. Onali, E. Calabrese, C. Petruzziello et al., "Endoscopic vs ultrasonographic findings related to Crohn's disease recurrence: a prospective longitudinal study at 3years," Journal of Crohn's \& Colitis, vol. 4, no. 3, pp. 319-328, 2010.

[9] L. Biancone, S. Onali, E. Calabrese et al., "Non-invasive techniques for assessing postoperative recurrence in Crohn's disease," Digestive and Liver Disease, vol. 40, no. 2, pp. S265S270, 2008.

[10] P. Rutgeerts, K. Geboes, G. Vantrappen, J. Beyls, R. Kerremans, and M. Hiele, "Predictability of the postoperative course of Crohn's disease," Gastroenterology, vol. 99, no. 4, pp. 956-963, 1990.

[11] R. McLeod, B. G. Wolff, S. Ross, R. Parkes, M. McKenzie, and Investigators of the CAST Trial, "Recurrence of Crohn's disease after ileocolic resection is not affected by anastomotic type," Randomized, Controlled Trial, vol. 52, no. 5, pp. 919-927, 2009.

[12] S. C. Ng, G. Arslan Lied, N. Arebi, R. K. Phillips, and M. A. Kamm, "Clinical and surgical recurrence of Crohn's disease after ileocolonic resection in a specialist unit," European Journal of Gastroenterology \& Hepatology, vol. 21, no. 5, pp. 551557, 2009.

[13] P. de Cruz, M. P. Bernardi, M. A. Kamm et al., "Postoperative recurrence of Crohn's disease: impact of endoscopic monitoring and treatment step-up," Colorectal Disease, vol. 15, no. 2, pp. 187-197, 2013.

[14] L. Biancone, G. S. Sica, E. Calabrese, S. Onali, C. Petruzziello, and F. Pallone, "Frequency and pattern of endoscopic recurrence in Crohn's disease patients with ileocolonic resection using a laparoscopic versus laparotomic approach: a prospective longitudinal study," American Journal of Gastroenterology, vol. 103, no. 3, pp. 809-811, 2008.

[15] S. Onali, E. Calabrese, C. Petruzziello et al., "Post-operative recurrence of Crohn's disease: a prospective study at 5 years," Digestive and Liver Disease, vol. 48, no. 5, pp. 489-494, 2016.

[16] F. L. Wolters, M. G. V. M. Russel, and R. W. Stockbrügger, "Systematic review: has disease outcome in Crohn's disease changed during the last four decades?," Alimentary Pharmacology \& Therapeutics, vol. 20, no. 5, pp. 483-496, 2004.

[17] J. G. Solon, J. P. Burke, S. R. Walsh, and J. C. Coffey, “The effect of NOD2 polymorphism on postsurgical recurrence in Crohn's disease," Inflammatory Bowel Diseases, vol. 19, no. 5, pp. 1099-1105, 2013.

[18] M. Alvarez-Lobos, J. I. Arostegui, M. Sans et al., "Crohn’s disease patients carrying Nod2/CARD15 gene variants have an increased and early need for first surgery due to stricturing disease and higher rate of surgical recurrence," Annals of Surgery, vol. 242, no. 5, pp. 693-700, 2005.

[19] B. P. Kline, T. Weaver, D. L. Brinton et al., "Clinical and genetic factors impact time to surgical recurrence after ileocolectomy for Crohn disease," Annals of Surgery, vol. Publish Ahead of Print, no. Xx, pp. 1-6, 2019.

[20] S. A. Fowler, A. N. Ananthakrishnan, A. Gardet et al., "SMAD3 gene variant is a risk factor for recurrent surgery in patients with Crohn's disease," Journal of Crohn's \& Colitis, vol. 8, no. 8, pp. 845-851, 2014.

[21] A. Germain, R. Guéant, M. Chamaillard, L. Bresler, J. Guéant, and L. Peyrin-Biroulet, "CARD8 gene variant is a risk factor for recurrent surgery in patients with Crohn's disease," Digestive and Liver Disease, vol. 47, no. 11, pp. 938-942, 2015.

[22] M. J. Meijer, M. A. C. Mieremet-Ooms, C. F. M. Sier et al., "Matrix metalloproteinases and their tissue inhibitors as prognostic indicators for diagnostic and surgical recurrence in Crohn's disease," Inflammatory Bowel Diseases, vol. 15, no. 1, pp. 84-92, 2009.

[23] D. Lissner, M. Schumann, A. Batra et al., "Monocyte and M1 macrophage-induced barrier defect contributes to chronic intestinal inflammation in IBD," Inflammatory Bowel Diseases, vol. 21, no. 6, pp. 1-1305, 2015.

[24] P. Salvador, D. C. Macías-Ceja, L. Gisbert-Ferrándiz et al., "CD16 + macrophages mediate fibrosis in inflammatory bowel disease," Journal of Crohn's and Colitis, vol. 12, no. 5, pp. 589-599, 2018.

[25] S. T. Gren and O. Grip, "Role of monocytes and intestinal macrophages in Crohn's disease and ulcerative colitis," Inflammatory Bowel Diseases, vol. 22, no. 8, pp. 1992-1998, 2016.

[26] F. Zorzi, I. Monteleone, M. Sarra et al., "Distinct profiles of effector cytokines mark the different phases of Crohn's disease," PLoS One, vol. 8, no. 1, article e54562, 2013.

[27] G. E. Diehl, R. S. Longman, J. Zhang et al., "Microbiota restricts trafficking of bacteria to mesenteric lymph nodes by $\mathrm{CX}_{3} \mathrm{CR} 1^{\text {hi }}$ cells," Nature, vol. 494, no. 7435 , pp. 116-120, 2013.

[28] H. Sokol, L. Brot, C. Stefanescu et al., "Prominence of ileal mucosa-associated microbiota to predict postoperative endoscopic recurrence in Crohn's disease," Gut, vol. 69, no. 3, pp. 462-472, 2020.

[29] A. van Gossum, O. Dewit, E. Louis et al., "Multicenter randomized-controlled clinical trial of probiotics (Lactobacillus johnsonii, LA1) on early endoscopic recurrence of Crohn's disease after ileo-caecal resection," Inflammatory Bowel Diseases, vol. 13, no. 2, pp. 135-142, 2007.

[30] A. Imdad, M. R. Nicholson, E. E. Tanner-Smith et al., "Fecal transplantation for treatment of inflammatory bowel disease," Cochrane Database of Systematic Reviews, vol. 11, no. 11, 2018.

[31] C. Y. Lai, J. Sung, F. Cheng et al., "Systematic review with meta-analysis: review of donor features, procedures and outcomes in 168 clinical studies of faecal microbiota transplantation," Aliment Pharmacol Ther, vol. 49, no. 4, pp. 354-363, 2019.

[32] G. Li, T. Zhang, W. Yang et al., "Gut microbiota patterns associated with somatostatin in patients undergoing pancreaticoduodenectomy: a prospective study," Cell Death Discovery, vol. 6, no. 1, 2020.

[33] H. Chen, Z. Chen, L. Shen et al., "Fecal microbiota transplantation from patients with autoimmune encephalitis modulates Th17 response and relevant behaviors in mice," Cell Death Discovery, vol. 6, no. 1, 2020.

[34] S. Paramsothy, R. Paramsothy, D. T. Rubin et al., "Faecal microbiota transplantation for inflammatory bowel disease: a systematic review and meta-analysis," Journal of Crohn's and Colitis, vol. 11, no. 10, pp. 1180-1199, 2017.

[35] M. Bsat, L. Chapuy, N. Baba et al., "Differential accumulation and function of proinflammatory 6-sulfo LacNAc dendritic 
cells in lymph node and colon of Crohn's versus ulcerative colitis patients," Journal of Leukocyte Biology, vol. 98, no. 4, pp. 671-681, 2015.

[36] M. Bsat, L. Chapuy, M. Rubio et al., "Differential pathogenic Th17 profile in mesenteric lymph nodes of Crohn's disease and ulcerative colitis patients," Frontiers in Immunology, vol. 10, pp. 2-10, 2019.

[37] L. Chapuy, M. Bsat, M. Rubio et al., "Transcriptomic analysis and high-dimensional phenotypic mapping of mononuclear phagocytes in mesenteric lymph nodes reveal differences between ulcerative colitis and Crohn's disease," Journal of Crohn's \& Colitis, vol. 14, no. 3, pp. 393-405, 2019.

[38] A. Sakuraba, T. Sato, N. Kamada, M. Kitazume, A. Sugita, and T. Hibi, "Th1/Th17 immune response is induced by mesenteric lymph node dendritic cells in Crohn's disease," Gastroenterology, vol. 137, no. 5, pp. 1736-1745, 2009.

[39] S. T. Peake, D. Bernardo, S. C. Knight, and A. L. Hart, "Homing marker expression on circulating dendritic cells correlates with different phenotypes of Crohn's disease," Journal of Crohn's \& Colitis, vol. 7, no. 7, pp. 594-596, 2013.

[40] A. L. Hart, S. C. Ng, E. Mann, H. O. al-Hassi, D. Bernardo, and S. C. Knight, "Homing of immune cells : role in homeostasis and intestinal inflammation," Inflammatory Bowel Diseases, vol. 16, no. 11, pp. 1969-1977, 2010.

[41] L. Chapuy, M. Bsat, H. Mehta et al., "Basophils increase in Crohn disease and ulcerative colitis and favor mesenteric lymph node memory $\mathrm{T}_{\mathrm{H}} 17 / \mathrm{T}_{\mathrm{H}} 1$ response," Journal of Allergy and Clinical Immunology, vol. 134, no. 4, pp. 978-981.e1, 2014.

[42] M. Allez, C. Auzolle, M. Ngollo et al., "T cell clonal expansions in ileal Crohn's disease are associated with smoking behaviour and postoperative recurrence," GUT, vol. 68, no. 11, pp. 1961-1970, 2019.

[43] M. Camus, S. Esses, B. Pariente et al., "Oligoclonal expansions of mucosal $\mathrm{T}$ cells in Crohn's disease predominate in NKG2D-expressing CD4 T cells," Mucosal Immunology, vol. 7, no. 2, pp. 325-334, 2014.

[44] C. G. Chapman, R. Yamaguchi, K. Tamura et al., "Characterization of T-cell receptor repertoire in inflamed tissues of patients with Crohn's disease through deep sequencing," Inflammatory Bowel Diseases, vol. 22, no. 6, pp. 1275-1285, 2016.

[45] T. Sathaliyawala, M. Kubota, N. Yudanin et al., "Distribution and compartmentalization of human circulating and tissueresident memory T cell subsets," Immunity, vol. 38, no. 1, pp. 187-197, 2013.

[46] D. Masopust and J. M. Schenkel, "The integration of T cell migration, differentiation and function," Nature Reviews Immunology, vol. 13, no. 5, pp. 309-320, 2013.

[47] A. R. Radmard, R. Eftekhar Vaghefi, S. A. Montazeri et al., "Mesenteric lymph nodes in MR enterography: are they reliable followers of bowel in active Crohn's disease ?," European Radiology, vol. 28, no. 10, pp. 4429-4437, 2018.

[48] A. Yamada, Y. Komaki, N. Patel et al., "The use of vedolizumab in preventing postoperative recurrence of Crohn's disease," Inflammatory bowel diseases, vol. 24, no. 3, pp. 502509, 2018.

[49] M. R. Laffin, R. N. Fedorak, E. Wine, B. Dicken, and K. L. Madsen, "A_BACH2_ gene variant is associated with postoperative recurrence of Crohn's disease," Journal of the American College of Surgeons, vol. 226, no. 5, pp. 902-908, 2018.
[50] M. L. Cupi, M. Sarra, I. Marafini et al., "Plasma cells in the mucosa of patients with inflammatory bowel disease produce granzyme B and possess cytotoxic activities," Journal of Immunology, vol. 192, no. 12, pp. 6083-6091, 2014.

[51] A. L. Hamilton, M. A. Kamm, P. de Cruz et al., "Serologic antibodies in relation to outcome in postoperative Crohn's disease," Journal of Gastroenterology and Hepatology, vol. 32, no. 6, pp. 1195-1203, 2017.

[52] G. Gathungu, Y. Zhang, X. Tian et al., "Impaired granulocytemacrophage colony-stimulating factor bioactivity accelerates surgical recurrence in ileal Crohn's disease," World Journal of Gastroenterology, vol. 24, no. 5, pp. 623-630, 2018.

[53] D. Fina, E. Franzè, L. Rovedatti et al., "Interleukin-25 production is differently regulated by TNF- $\alpha$ and TGF- $\beta 1$ in the human gut," Mucosal Immunology, vol. 4, no. 2, pp. 239244, 2011.

[54] E. Franzè, I. Monteleone, M. L. Cupi et al., "Interleukin-34 sustains inflammatory pathways in the gut," Clinical Science, vol. 129, no. 3, pp. 271-280, 2015.

[55] E. Franzè, I. Marafini, V. de Simone et al., "Interleukin-34 induces CC-chemokine ligand 20 in gut epithelial cells," Journal of Crohn's \& Colitis, vol. 10, no. 1, pp. 87-94, 2016.

[56] V. De Simone, G. Ronchetti, E. Franzè et al., "Interleukin-21 sustains inflammatory signals that contribute to sporadic colon tumorigenesis," Oncotarget, vol. 6, no. 12, pp. 99089923, 2015.

[57] M. Sarra, M. L. Cupi, I. Monteleone et al., "IL-15 positively regulates IL-21 production in celiac disease mucosa," Mucosal Immunology, vol. 6, no. 2, pp. 244-255, 2013.

[58] F. Caprioli, M. Sarra, R. Caruso et al., "Autocrine regulation of IL-21 production in human T lymphocytes," Journal of Immunology, vol. 180, no. 3, pp. 1800-1807, 2008.

[59] I. Marafini, I. Monteleone, D. di Fusco et al., "TNF- $\alpha$ producing innate lymphoid cells (ILCs) are increased in active celiac disease and contribute to promote intestinal atrophy in mice," PLoS One, vol. 10, no. 5, article e0126291, 2015.

[60] C. Ruffolo, M. Scarpa, D. Faggian et al., "Subclinical intestinal inflammation in patients with Crohn's disease following bowel resection: a smoldering fire," Journal of Gastrointestinal Surgery, vol. 14, no. 1, pp. 24-31, 2010.

[61] E. Iaculli, M. Agostini, L. Biancone et al., "C-reactive protein levels in the perioperative period as a predictive marker of endoscopic recurrence after ileo-colonic resection for Crohn's disease," Cell Death Discovery, vol. 2, no. 1, 2016.

[62] T. Yamamoto, S. Umegae, T. Kitagawa, and K. Matsumoto, "Mucosal cytokine production during remission after resection for Crohn's disease and its relationship to future relapse," Alimentary Pharmacology \& Therapeutics, vol. 19, no. 6, pp. 671-678, 2004.

[63] B. Meresse, P. Rutgeerts, H. Malchow et al., "Low ileal interleukin 10 concentrations are predictive of endoscopic recurrence in patients with Crohn's disease," Gut, vol. 50, no. 1, pp. 25-28, 2002.

[64] R. Gonsky, P. Fleshner, R. L. Deem et al., "Association of ribonuclease T2 gene polymorphisms with decreased expression and clinical characteristics of severity in Crohn's disease," Gastroenterology, vol. 153, no. 1, pp. 219-232, 2017.

[65] M. Regueiro, B. G. Feagan, B. Zou et al., "Infliximab reduces endoscopic, but not clinical, recurrence of Crohn's disease after ileocolonic resection," Gastroenterology, vol. 150, no. 7, pp. 1568-1578, 2016. 
[66] A. Rönnblom, T. Holmström, U. Karlbom, H. Tanghöj, M. Thörn, and D. Sjöberg, "Clinical course of Crohn's disease during the first 5 years. Results from a population-based cohort in Sweden (ICURE) diagnosed 2005-2009*," Scandinavian Journal of Gastroenterology, vol. 52, no. 1, pp. 81-86, 2017.

[67] M. Collins, H. Sarter, C. Gower-Rousseau et al., "Previous exposure to multiple anti-TNF is associated with decreased efficiency in preventing postoperative Crohn's disease recurrence," Journal of Crohn's and Colitis, vol. 11, no. 3, pp. 281288, 2017.

[68] H. Kotanagi, K. Kramer, V. W. Fazio, and R. E. Petras, "Do microscopic abnormalities at resection margins correlate with increased anastomotic recurrence in Crohn' $s$ disease ? Retrospective analysis of 100 cases," Diseases of the Colon and Rectum, vol. 34, no. 10, pp. 909-916, 1977.

[69] L. Pennington, S. R. Hamilton, T. M. Bayless, and J. O. H. N. L. CAMERON, "Surgical management of Crohn's disease. Influence of disease at margin of resection," Annals of Surgery, vol. 192, no. 3, pp. 311-318, 1980.

[70] V. W. Fazio, F. Marchetti, M. Church et al., "Effect of resection margins on the recurrence of Crohn's disease in the small bowel," Annals of Surgery, vol. 224, no. 4, pp. 563-573, 1996.

[71] K. Poredska, L. Kunovsky, F. Marek et al., "The influence of microscopic inflammation at resection margins on early postoperative endoscopic recurrence after ileocaecal resection for Crohn's disease," Journal of Crohn's and Colitis, vol. 14, no. 3, pp. 361-368, 2020.

[72] K. A. T. G. M. Wasmann, J. van Amesfoort, M. L. van Montfoort, L. Koens, W. A. Bemelman, and C. J. Buskens, "The predictive value of inflammation at ileocecal resection margins for postoperative Crohn's recurrence: a cohort study," Inflammatory Bowel Diseases, vol. 26, no. 11, pp. 16911699, 2020.

[73] C. J. M. Simillis, M. Jacovides, G. E. Reese, T. Yamamoto, and P. P. Tekkis, "Meta-analysis of the role of granulomas in the recurrence of Crohn disease," Diseases of the Colon \& Rectum, vol. 53, no. 2, pp. 177-185, 2010.

[74] M. Ferrante, G. de Hertogh, T. Hlavaty et al., "The value of myenteric plexitis to predict early postoperative Crohn's disease recurrence," Gastroenterology, vol. 130, no. 6, pp. 15951606, 2006.

[75] B. Lemmens, A. de Buck van Overstraeten, I. Arijs et al., "Submucosal plexitis as a predictive factor for postoperative endoscopic recurrence in patients with Crohn's disease undergoing a resection with ileocolonic anastomosis: results from a prospective single-centre study," Journal of Crohn's and Colitis, vol. e11, no. 2, pp. 212-220, 2017.

[76] A. Bressenot, J. Chevaux, N. Williet et al., "Submucosal plexitis as a predictor of postoperative surgical recurrence in Crohn's disease," Inflammatory Bowel Diseases, vol. 19, no. 8, pp. 1654-1661, 2013.

[77] Y. Li, Y. Ge, W. Zhu et al., "Increased enteric glial cells in proximal margin of resection is associated with postoperative recurrence of Crohn's disease," Journal of Gastroenterology and Hepatology, vol. 33, no. 3, pp. 638-644, 2018.

[78] A. Bressenot and L. Peyrin-biroulet, "Histologic features predicting postoperative Crohn' s disease," Inflammatory Bowel Diseases, vol. 21, no. 2, pp. 468-475, 2015.

[79] I. Cioffi, N. Imperatore, O. di Vincenzo et al., "Evaluation of nutritional adequacy in adult patients with Crohn's disease: a cross-sectional study," European Journal of Nutrition, vol. 59, no. 8, pp. 3647-3658, 2020.

[80] T. Matstji, T. Sakurai, and T. Yao, "Nutritional therapy for Crohn's disease in Japan," Journal of Gastroenterology, vol. 40, no. S16, pp. 25-31, 2005.

[81] T. Yamamoto, M. Nakahigashi, S. Umegae, T. Kitagawa, and K. Matsumoto, "Impact of long-term enteral nutrition on clinical and endoscopic recurrence after resection for Crohn's disease: a prospective, non-randomized, parallel, controlled study," Alimentary Pharmacology \& Therapeutics, vol. 25, no. 1, pp. 67-72, 2007.

[82] T. Yamamoto, M. Shiraki, M. Nakahigashi, S. Umegae, and K. Matsumoto, "Enteral nutrition to suppress postoperative Crohn's disease recurrence: a five-year prospective cohort study," International Journal of Colorectal Disease, vol. 28, no. 3, pp. 335-340, 2013.

[83] N. Ohara, T. Mizushima, H. Iijima et al., "Adherence to an elemental diet for preventing postoperative recurrence of Crohn's disease," Surgery Today, vol. 47, no. 12, pp. 15191525, 2017.

[84] G. S. Sica, S. di Carlo, G. Tema et al., “Treatment of peri-anal fistula in Crohn's disease," World Journal of Gastroenterology, vol. 20, no. 37, pp. 13205-13210, 2014.

[85] S. Sibio, A. di Giorgio, M. Campanelli et al., "Ambulatory surgery for perianal Crohn's disease: study of feasibility," Gastroenterology Research and Practice, vol. 2018, 7 pages, 2018.

[86] the Italian Society of Colorectal Surgery SICCR, G. Pellino, D. S. Keller et al., "Inflammatory bowel disease position statement of the Italian Society of Colorectal Surgery (SICCR): Crohn's disease," Techniques in Coloproctology, vol. 24, no. 5, pp. 421-448, 2020.

[87] the Italian Society of Colorectal Surgery (SICCR), G. Pellino, D. S. Keller et al., "Inflammatory bowel disease (IBD) position statement of the Italian Society of Colorectal Surgery (SICCR): general principles of IBD management," Techniques in Coloproctology, vol. 24, no. 2, pp. 105-126, 2020.

[88] the Italian Society of Colorectal Surgery SICCR, G. Pellino, D. S. Keller et al., "Inflammatory bowel disease position statement of the Italian Society of Colorectal Surgery (SICCR): ulcerative colitis," Techniques in Coloproctology, vol. 24, no. 5, pp. 397-419, 2020.

[89] SICCR Current Status of Crohn's Disease Surgery Collaborative, V. Celentano, G. Pellino et al., "National variations in perioperative assessment and surgical management of Crohn's disease: a multicentre study," Colorectal Disease, pp. 1-11, 2020.

[90] A. Ikeda, N. Miyoshi, S. Fujino et al., "A novel predictive nomogram for early endoscopic recurrence after intestinal resection for Crohn's disease," Digestion, vol. 100, no. 4, pp. 269-276, 2019.

[91] V. Anumakonda, B. Hayee, and G. Chung-Faye, "Remission and relapse of Crohn's disease following autologous haematopoietic stem cell transplantation for non-Hodgkin's lymphoma," Gut, vol. 56, no. 9, p. 1325, 2007.

[92] J. A. Snowden, J. Panés, T. Alexander et al., "Autologous haematopoietic stem cell transplantation (AHSCT) in severe Crohn's disease : a review on behalf of ECCO and EBMT," Journal of Crohn's and Colitis, vol. 12, no. 4, pp. 476-488, 2018.

[93] X. Qiu, J.-R. Feng, L.-P. Chen et al., "Efficacy and safety of autologous hematopoietic stem cell therapy for refractory Crohn's disease," Medicine, vol. 96, no. 26, p. e7381, 2017. 
[94] C. J. Hawkey, M. Allez, M. M. Clark et al., "Autologous hematopoetic stem cell transplantation for refractory Crohn disease a randomized clinical trial," Journal of the American Medical Association, vol. 314, no. 23, pp. 2524-2534, 2015.

[95] J. O. Lindsay, M. Allez, M. Clark et al., “Autologous stem-cell transplantation in treatment-refractory Crohn's disease: an analysis of pooled data from the ASTIC trial," The Lancet Gastroenterology \& Hepatology, vol. 2, no. 6, pp. 399-406, 2017.

[96] J. A. Snowden, A. Ansari, S. Sachchithanantham et al., "Autologous stem cell transplantation in severe treatmentresistant Crohn's disease: long-term follow-up of UK patients treated on compassionate basis," QJM, vol. 107, no. 11, pp. 871-877, 2014.

[97] J. A. Snowden, Behalf of the Autologous Stem Cell Transplantation In Refractory CD - Low Intensity Therapy Evaluation Study Investigators, C. Hawkey et al., "Autologous stem cell transplantation in refractory Crohn's disease-low intensity therapy evaluation (ASTIClite): study protocols for a multicentre, randomised controlled trial and observational follow up study," BMC Gastroenterology, vol. 19, pp. 1-14, 2019.

[98] G. S. Sica, E. Iaculli, D. Benavoli et al., "Laparoscopic versus open ileo-colonic resection in Crohn's disease: short- and long-term results from a prospective longitudinal study," Journal of Gastrointestinal Surgery, vol. 12, no. 6, pp. 1094$1102,2008$.

[99] B. V. M. Dasari, D. McKay, K. Gardiner, and Cochrane Colorectal Cancer Group, "Laparoscopic versus open surgery for small bowel Crohn's disease," Cochrane Database of Systematic Reviews, vol. 19, no. 1, 2011.

[100] G. S. Sica and L. Biancone, "Surgery for inflammatory bowel disease in the era of laparoscopy," World Journal of Gastroenterology, vol. 19, no. 16, pp. 2445-2448, 2013.

[101] G. S. Sica, S. Di Carlo, S. D’Ugo et al., “Minimal open access ileocolic resection in complicated Crohn's disease of the terminal ileum," Gastroenterology Research and Practice, vol. 2020, Article ID 6019435, 6 pages, 2020.

[102] S. D’Ugo, F. Romano, S. Sibio et al., "Impact of surgery on quality of life in Crohn's disease: short- and mid-term follow-up," Updates in Surgery, vol. 72, no. 3, pp. 773-780, 2020.

[103] G. S. Sica, S. di Carlo, L. Biancone, P. Gentileschi, F. Pallone, and A. L. Gaspari, "Single access laparoscopic ileocecal resection in complicated Crohn's disease," Surgical Innovation, vol. 17, no. 4, pp. 359-360, 2010.

[104] P. Sileri, G. Sica, P. Gentileschi et al., "Ischemic preconditioning protects intestine from prolonged ischemia," Transplantation Proceedings, vol. 36, no. 2, pp. 283-285, 2004.

[105] The Cochrane Collaboration, P. Y. G. Choy, I. P. Bissett, J. G. Docherty, B. R. Parry, and A. Merrie, "Stapled versus handsewn methods for ileocolic anastomoses," Cochrane Database of Systematic Reviews, vol. 3, 2007.

[106] C. Simillis, S. Purkayastha, T. Yamamoto, S. A. Strong, A. W. Darzi, and P. P. Tekkis, "A meta-analysis comparing conventional end-to-end anastomosis vs. other anastomotic configurations after resection in Crohn's disease," Diseases of the Colon and Rectum, vol. 50, no. 10, pp. 1674-1687, 2007.

[107] M. Scarpa, I. Angriman, M. Barollo et al., "Role of stapled and hand-sewn anastomoses in recurrence of Crohn's disease," Hepatogastroenterology, vol. 51, no. 58, pp. 1053-1057, 2004.
[108] T. Kono, T. Ashida, Y. Ebisawa et al., "A new antimesenteric functional end-to-end handsewn anastomosis: surgical prevention of anastomotic recurrence in Crohn's disease," Diseases of the Colon and Rectum, vol. 54, no. 5, pp. 586-592, 2011.

[109] C. J. Coffey, M. G. Kiernan, S. M. Sahebally et al., "Inclusion of the mesentery in ileocolic resection for Crohn's disease is associated with reduced surgical recurrence," Journal of Crohn's and Colitis, vol. 12, no. 10, pp. 1139-1150, 2018.

[110] A. Fichera, M. Zoccali, and T. Kono, "Antimesenteric functional end-to-end handsewn (Kono-S) anastomosis," Journal of Gastrointestinal Surgery, vol. 16, no. 7, pp. 1412-1416, 2012.

[111] H. Katsuno, K. Maeda, T. Hanai, K. Masumori, Y. Koide, and T. Kono, "Novel antimesenteric functional end-to-end handsewn (Kono-S) anastomoses for Crohn's disease: a report of surgical procedure and short-term outcomes," Digestive Surgery, vol. 32, no. 1, pp. 39-44, 2015.

[112] N. Shimada, H. Ohge, T. Kono et al., "Surgical recurrence at anastomotic site after bowel resection in Crohn's disease : comparison of Kono-S and end-to-end anastomosis," Journal of Gastrointestinal Surgery, vol. 23, no. 2, pp. 312-319, 2019.

[113] W. A. Bemelman, J. Warusavitarne, G. M. Sampietro et al., "ECCO-ESCP consensus on surgery for Crohn's disease," Journal of Crohn's and Colitis, vol. 12, no. 1, pp. 1-16, 2017.

[114] G. Luglio, A. Rispo, N. Imperatore et al., "Surgical prevention of anastomotic recurrence by excluding mesentery in Crohn's disease: the SuPREMe-CD study-a randomized clinical trial," Annals of Surgery, vol. 272, no. 2, pp. 210-217, 2020.

[115] F. Michelassi, R. D. Hurst, M. Melis et al., "Side-to-side isoperistaltic strictureplasty in extensive Crohn's disease," Annals of Surgery, vol. 232, no. 3, pp. 401-408, 2000.

[116] A. de Buck van Overstraeten, S. Vermeire, D. Vanbeckevoort et al., "Modified side-to-side isoperistaltic strictureplasty over the ileocaecal valve: an alternative for ileocaecal resection in extensive terminal ileal Crohn's disease," Journal of Crohn's and Colitis, vol. 10, no. 4, pp. 437-442, 2016.

[117] T. Yamamoto, S. Umegae, T. Kitagawa, and K. Matsumoto, "Postoperative change of mucosal inflammation at strictureplasty segment in Crohn's disease: cytokine production and endoscopic and histologic findings," Diseases of the Colon and Rectum, vol. 48, no. 4, pp. 749-757, 2005.

[118] F. Michelassi, D. Mege, M. Rubin, and R. D. Hurst, "Longterm results of the side-to-side isoperistaltic strictureplasty in Crohn disease," Annals of Surgery, vol. 272, no. 1, pp. 130-137, 2020.

[119] M. Fazi, F. Giudici, C. Luceri, M. Pronestì, F. Tonelli, and M. Francesco Tonelli, "Long-term results and recurrencerelated risk factors for Crohn disease in patients undergoing side-to-side isoperistaltic strictureplasty," JAMA Surgery, vol. 151, no. 5, pp. 452-460, 2016.

[120] C. J. B. W. Buskens and W. A. Bemelman, "Inclusion of the mesentery in ileocolic resection for Crohn's disease is associated with reduced surgical recurrence: editorial by Coffey et al.," Journal of Crohn's \& Colitis, vol. 12, no. 10, pp. 1137-1138, 2018.

[121] P.-Y. von der Weid, S. Rehal, and J. G. P. Ferraz, "Role of the lymphatic system in the pathogenesis of Crohn's disease," Current Opinion in Gastroenterology, vol. 27, no. 4, pp. 335-341, 2011. 
[122] G. J. Randolph, S. Bala, J.-F. Rahier et al., "Lymphoid aggregates remodel lymphatic collecting vessels that serve mesenteric lymph nodes in Crohn disease," The American Journal of Pathology, vol. 186, no. 12, pp. 3066-3073, 2016.

[123] E. D. Rivera, J. C. Coffey, D. Walsh, and E. D. Ehrenpreis, "The mesentery, systemic inflammation, and Crohn's disease," Inflammatory Bowel Diseases, vol. 25, no. 2, pp. 226234, 2019.

[124] E. Candi, M. Tesauro, C. Cardillo et al., "Metabolic profiling of visceral adipose tissue from obese subjects with or without metabolic syndrome," Biochemical Journal, vol. 475, no. 5, pp. 1019-1035, 2018.

[125] EuroSurg Collaborative, "Body mass index and complications following major gastrointestinal surgery: a prospective, international cohort study and meta-analysis," Colorectal Disease, vol. 20, no. 8, pp. O215-O225, 2018.

[126] E. S. Collaborative, "EuroSurg : a new European studentdriven research network in surgery," Colorectal Disease, vol. 18, no. 2, pp. 214-215, 2016.

[127] J. H. M. van der Meer, K. A. T. G. M. Wasmann, J. D. W. van der Bilt et al., "Anatomical variation in mesenteric macrophage phenotypes in Crohn's disease," Clinical and Translational Gastroenterology, vol. 11, no. 8, article e00198, 2020.

[128] A. Coope, L. B. Pascoal, J. D. Botezelli et al., "ER stress activation in the intestinal mucosa but not in mesenteric adipose tissue is associated with inflammation in Crohn's disease patients," PLoS One, vol. 14, no. 9, article e0223105, 2019.

[129] V. Celentano, E. Garofalo, A. Spinelli et al., "Video-laparoscopic assessment of the small bowel in Crohn's disease: a comparative study to evaluate surgeons' inter-observer variability," Surgical Endoscopy, 2020.

[130] C. Nyabanga, G. Kochhar, G. Costa, B. Soliman, B. Shen, and K. Abu-Elmagd, "Management of Crohn's disease in the new era of gut rehabilitation and intestinal transplantation," Inflammatory Bowel Diseases, vol. 22, no. 7, pp. 1763-1776, 2016.

[131] H. Fahad, K. Abu-elmagd, B. Lashner, and C. Fiocchi, "Recurrence of Crohn's disease after small bowel transplantation : fact or fiction," Inflammatory Bowel Diseases, vol. 26, no. 1, pp. 21-23, 2019. 